\title{
Nuevas perspectivas en materia de resolución del contrato por incumplimiento
}

\section{New Perspectives on the Dissolution of Contract for Failure}

Mauro Paladini*

Fecha de recepción: 31 de marzo de 2009

Fecha de aprobación: 30 de abril de 2009

\section{Resumen}

Una visión histórica y comparativa del instituto de la resolución por incumplimiento, muestra la conveniencia de optar por el modelo sustancial antes que por el modelo judicial, es decir, optar por la declaración unilateral por parte del contratante fiel, a fin de disolver el vínculo contractual quedando la actividad judicial como mera verificación. El modelo judicial conserva vigencia en los sistemas latinoamericanos, mas no así en las modernas regulaciones europeas ni en los sistemas anglosajones.

\section{Palabras clave}

Contrato, incumplimiento, resolución, desistimiento.

Profesor de la Universitá di Brescia -Italia y profesor invitado de la Maestría en contratación pública y privada de la Universidad Santo Tomás de Bogotá.

Traducción del italiano por Luis Cárdenas Rodríguez, Profesor de Derecho Civil de la Universidad Privada Los Ángeles (Lima), bajo el cuidado de Olenka Woolcott Oyague, Profesora de Derecho Civil de la Universidad de Lima. Se conserva la forma de citación original 


\begin{abstract}
A new comparative and historical view of the institute of the resolution for breach shows the convenience of choosing the the substantial model rather than the judicial one, it means the unilateral declaration of the contractor faithful to dissolve the contractual relationship establishing the judicial activity as mere verification. The judicial model retains validation in Latin America systems, but not in the modern European regulations or in the Anglo-Saxon systems.
\end{abstract}

\title{
Key words
}

Ccontract, breach, resolution, withdrawal.

\section{LOS ORÍGENES HISTÓRICOS DE LA RESOLUCIÓN POR INCUMPLIMIENTO: DE LA LEX COMMISSORIA A LA CONDICIÓN RESOLUTORIA TÁCITA (ART. 1184 CODE NAPOLEÓN)}

Son dos los modelos de resolución del contrato, que los diversos ordenamientos adoptan en presencia del incumplimiento de uno de los contratantes:

- El modelo judicial, que impone al acreedor de la prestación incumplida dirigirse al juez para obtener una sentencia constitutiva, que produzca la extinción de las respectivas obligaciones de las partes,

- Y el modelo sustancial, en el cual la resolución se produce por efecto de una declaración unilateral del contratante insatisfecho, cuya legitimidad podrá ser sucesivamente evaluada por el juez con una mera verificación de la subsistencia de los requisitos previstos por la ley.

En el modelo judicial, el juez es considerado la sola autoridad en grado de privar al contrato de su fuerza vinculante entre las partes.

En el modelo sustancial es el acreedor el que mide sus propios intereses y decide que el vínculo del contrato, violado por el incumplimiento -o por el retraso o por el inexacto cumplimiento-, no corresponde más a sus intereses.
La declaración del acreedor, que produce la resolución del contrato, tiene diversas denominaciones en los varios ordenamientos. En el sistema italiano se usa el término recesso; en el BGB alemán es definido der Rücktritt; en otros ordenamientos y en muchos textos normativos internacionales se habla simplemente de declaración de resolución; en Colombia, si bien el problema de la distinción entre modelo sustancial y modelo judicial está aún en discusión, me parece que el término que se debería considerar apropiado -como se deduce del artículo 1882 del Código Civil- es desistimiento.

En el origen de esta duplicidad de modelos hay razones históricas, que hunden sus raíces en el mismo origen del moderno instituto de la resolución por incumplimiento.

Según una orientación difundida entre los estudiosos del derecho romano ${ }^{1}$, los orígenes históricos de la resolución por incumplimiento deben ser buscados en la lex commissoria, cláusula accesoria de la compraventa, en virtud de la cual la propiedad de la cosa retornaba al vendedor si el comprador no pagaba el precio². Sin embargo,

1 Cerami, Risoluzione (dir. rom.), en Enc. Dir., Giuffré, Milano, 1989, 1287, según el cual "la lex commissoria absolvía, en el ámbito de la compraventa, una función comparable, a grandes líneas, a la desarrollada por la así llamada condición resolutoria tácita, acogida por nuestro código civil" (art. 1453 c.c.). La lex commissoria es definida un "subrogado convencional" de la resolución por incumplimiento por Boyer, Recherches historiques sur la résolution des contrats (origines de l'article 1184 c civ), París, 1924, 105 ss.

2 Como explica en forma difusa Arangio-Ruiz V. (Istituzione di diritto romano, Napoli, 1983, XIV ed., 89-90), originariamente, la lex 
en el derecho romano la disolución del contrato se verificaba solamente en consecuencia de la expresa declaración del vendedor de querer valerse de la lex commissoria, según un esquema que podríamos referir al modelo que hace poco hemos definido como "sustancial".

Según otra opinión ${ }^{3}$, el origen de la resolución por incumplimiento debe ser buscado en el derecho canónico que admitía, para el caso de incumplimiento de una obligación correlativa, una condición tácita de la validez de la promesa que, en cuanto asumida con juramento, se debía entender pronunciada incluso delante de Dios ${ }^{4}$. La resolución era conforme a la buena fe y la regla fides non servanda est ei qui frangit fidem constituía la sanción proporcionada frente a la parte que incumplía 5 .

Además, a diferencia de la lex commissoria, la condición tácita del Derecho Canónico no producía la extinción de la obligación ni automáticamente ni como consecuencia de la declaración de querer dar por resuelto el contrato, antes bien exigía el

commissoria no operaba como un pacto resolutorio, antes bien como cláusula que mantenía la propiedad de la cosa en cabeza del vendedor no obstante la traditio. En virtud de ello, luego de la falta de pago del precio, el vendedor, siendo todavía propietario, podía actuar en reivindicación frente al comprador. Después, la lex commissoria fue interpretada como pacto resolutorio agregado al contrato consensual de compraventa en sí perfecto, con la consecuencia de que, verificado el incumplimiento, el vendedor no podía actuar en reivindicación, sino que disponía de la acción contractual para la restitución de la res. En fin, en el derecho justinianeo, se afirma la idea por la cual, verificarse de la condición (el incumplimiento), la propiedad retorna automáticamente al vendedor, que puede accionar, por tanto, con la acción de reivindicación. En esta época se puede hablar, por ende, de "eficacia real" de la resolución, contrapuesta a la eficacia obligatoria que tenía en la época clásica.

3 Magno, D. Studi sul negozio condizionato, Roma, 1930, § 47; más recientemente, Petronio, U. Risoluzione (dir. interm.), en Enc. Dir., Giuffré, Milano, 1989, 1296-1298; en la doctrina francesa, Cassin V., Réflexions sur la résolution judiciaire des contrats pour inexécution, en Rev. Trim. Dr. Civ., 1945, 162-165, cuya opinión es retomada y compartida por Ghestin J., La résolution pour inexécution (en droit francais), en II contratto inadempiuto, cit., 111. Para la profundización de las características y de las fuentes de la resolución por incumplimiento en el Derecho Canónico, Dell'aquila E., La resolución, cit., 45-63.

4 Bartolo: Non enim iurando promitto parti, sed magis Deo.

5 A esta interpretación "sancionatoria" de la resolución del contrato en el Derecho Canónico se adhiere, en particular, Auletta G.G., La risoluzione, cit., 41 ss. recurso al juez, quien era la única autoridad titular del poder discrecional absoluto de pronunciar 0 negar la resolución.

El Código francés de 1804 recogió, en parte, ambos modelos, acogiendo sea la condición resolutoria tácita sea el perfil de la naturaleza judicial de la resolución de origen canónico. El art. 1184 estableció, en efecto, que la condición resolutoria está siempre sobreentendida en los contratos sinalagmáticos en el caso en que una de las partes no cumpla su obligación, pero precisó inmediatamente que en tal caso -y, es decir, a diferencia de lo previsto por el precedente art. 1183 referido a la condición como elemento accidental del contratoel contrato no puede ser resuelto de derecho. La parte fiel puede escoger entre constreñir a la otra a cumplir la prestación posible, o bien demandar la resolución con los daños y los intereses.

El recurso al juez para obtener la resolución del contrato era inevitable en consideración de la contextual previsión del poder judicial de conceder al deudor "...una dilación de acuerdo con las circunstancias" ${ }^{\prime \prime}$. Ya que, en efecto, en el asíllamado "término de gracia" el deudor podía remediar la inexactitud de la prestación o bien sanar el propio retardo mediante el cumplimiento tardío, sólo el juez podía sancionar la disolución de la relación contractual después de haber evaluado las características del incumplimiento y la eventual oportunidad de conceder al deudor una "dilación"7.

6 El tercer párrafo del art. 1184 c.c. fr. -aún hoy vigente- establece, en efecto, que "La résolution doit demandée en justice, et il peut être accordé au défendeur un délai selon les circonstances".

7 El poder de conceder una dilación para el cumplimiento se remonta al derecho consuetudinario francés, en el cual el recurso al juez preveía una primera fase que tenía como fin la fijación de un término para el cumplimiento tardío bajo la conminación de la resolución, y una segunda instancia dirigida a obtener el pronunciamiento de resolución judicial previa determinación del persistente incumplimiento y del infructuoso vencimiento del plazo. Por tanto, el código francés, aboliendo el doble recurso al juez "simplificó" el procedimiento de resolución del contrato, limitandose a prever el poder judicial de conceder un plazo al deudor en el ámbito del juicio de disolución ya instaurado por el acreedor. Para tales referencias y para las relativas puntuales citas, Smiroldo, Profili, cit., 257-258. 


\section{LA RESOLUCIÓN DEL CONTRATO EN EL CÓDIGO CIVIL ITALIANO DE 1865 Y EN EL CÓDIGO DE COMERCIO ITALIANO DE 1882}

También el Código Civil italiano de 1865, inspirándose en el modelo francés, acogió el instituto de la condición resolutoria tácita por incumplimiento (art. $1165^{\circ}$ ) y atribuyó al juez el poder de pronunciar la resolución del contrato y de conceder al demandado una dilación "según las circunstancias".

También en tal caso, la elección legislativa en favor del modelo "judicial" de resolución aparece inspirada en el intento de atribuir a la discrecionalidad del juez sea la evaluación de los presupuestos de oportunidad para pronunciar la disolución del contrato sea la liquidación del resarcimiento del daño consiguiente al incumplimiento contractual.

El Código de Comercio italiano de 1882, en cambio, prohibía al juez, expresamente, consentir al deudor el cumplimiento tardío dentro de un término dilatorio (art. 42) ${ }^{9}$.

Las razones de esta diversidad fueron individualizadas por la doctrina en las "características especiales de las obligaciones comerciales y en las exigencias del comercio, el cual vive y florece en la seguridad de los compromisos asumidos"10. La obligación comercial, además, era considerada "esencialmente circulable", a diferencia de la civil "que tiende a individualizarse entre las personas

8 “La condición resolutoria está siempre sobreentendida en los contratos bilaterales, para el caso en que una de las partes no satisfaga su obligación.

En este caso el contrato no es disuelto de Derecho. La parte hacia la cual no fue cumplida la obligación, tiene la elección o de constreñir a la otra al cumplimiento del contrato, cuando sea posible, o demandar su disolución, además del resarcimiento de los daños en ambos casos.

La resolución del contrato se debe demandar judicialmente, y puede ser concedida al demandado una dilación según las circunstancias".

9 En las obligaciones comerciales el juez no puede otorgar la dilación permitida en el art. 1165 del código civil.

10 Parisi, Obbligazioni (diritto commerciale), cit., 957. de los primeros contratantes"11; por ello, la eventual dilación concedida a un deudor expone al acreedor a que sea deudor, a su vez, frente a un tercer sujeto, con el riesgo del incumplimiento y del deber de pago de daños ${ }^{12}$.

\section{LA RESOLUCIÓN AUTOMÁTICA POR INCUMPLIMIENTO EN EL CÓDIGO CIVIL PORTUGUÉS DE 1857}

Mientras el Código Civil español seguiría las huellas de las codificaciones francesa e italiana, un moderno modo de ver el derecho a la resolución del contrato es acogido en el Código Civil portugués de 1857, cuyo art. 709 establecía, para los contratos bilaterales, que, en caso de incumplimiento de una de las partes, la otra se podía considerar no más obligada al cumplimiento de la prestación que le correspondía. La necesidad de recurrir al juez era prevista solamente en el caso de acción para el cumplimiento de la prestación incumplida o para el resarcimiento del daño sufrido.

Por ende, aun no estando prevista una declaración de resolución, tal Código optaba abiertamente por el modelo de la resolución automática, afirmando que la pretensión de la parte que no había incumplido de no considerarse más vinculada al cumplimiento de su propia obligación constituía un efecto ex lege del incumplimiento de la prestación correspondiente, y atribuía, en consecuencia, al juez, una función de mero reconocimiento de la producida pérdida de los efectos obligatorios del contrato.

También la reforma de $1930^{13}$ confirmó tal planteamiento, extendiéndolo -como en el BGB-también al caso en que la falta de cumplimiento de la contraparte se hubiera debido a la imposibilidad (material o jurídica) de cumplir la propia obligación.

\footnotetext{
11 Parisi, ibidem.

12 Así, Vidari, Corso di diritto commerciale, III, Milano, 1893, 2422.

13 Ley del 16 de diciembre de 1930
} 


\section{LA RESOLUCIÓN EN EL CÓDIGO CIVIL ESPAÑOL DE 1889}

El Código español acoge el modelo de la condición resolutoria tácita, que ya había sido adoptado por Ios códigos civiles francés e italiano, estableciendo en el art. 1124 que "la facultad de resolver las obligaciones se entiende implícita en las recíprocas, para el caso de que uno de los obligados no cumpliere lo que le incumbe".

Mencionando, no obstante, en vez de la condición resolutoria tácita, la "facultad" de resolver la obligación, la doctrina y la jurisprudencia española han elaborado una diversa concepción en torno a la naturaleza jurídica y a las modalidades de ejercicio de la resolución del contrato, que parecen incluso ponerse en contraste con lo que expresamente sanciona el tercer párrafo del propio art. 1124, según el cual: "el Tribunal decretará la resolución que se reclame, a no haber causas justificadas que le autoricen para señalar plazo".

La indeterminación del concepto de "facultad" ha permitido, en efecto, llegar a la conclusión por la cual la resolución del contrato se puede producirs no sólo mediante el pronunciamiento constitutivo del juez, sino también por efecto de la declaración unilateral comunicada al deudor por la parte que cumplió ${ }^{14}$.

En el caso en que el deudor se adhiera a la declaración de resolución, se perfecciona una suerte de

14 Sobre el punto, el sintético y nítido examen de Diez Picazo, Una opinión española sobre el proyecto ítalo-francés de código de las obligaciones, en Le projet franco-italien du Code des Obligations, bajo el cuidado de M. Rotondi, Padova, 1980. Para una reconstrucción más analítica de la evolución doctrinaria, Álvarez Vigaray, La resolución de los contratos bilaterales por incumplimiento, $3^{\text {a }}$ ed., Granata, 2003, 73 ss., el cual refiere la elaboración de otros autores en los cuales, si bien implícitamente, pareciera que la facultad de resolución, en vista de lo dispuesto por el art. 1124, $3^{\text {er }}$ párrafo, se debiera entender sólo como judicial: así, por ejemplo, Manresa, Comentarios al Código Civil español, VIII, vol. 1, $5^{\text {a }}$ ed., Madrid, 1950, 353. Según el autor, en el Derecho español subsisten tres formas de resolución por incumplimiento: judicial, consensual y por declaración unilateral del acreedor resolución consensual, que consiente en entender definitivamente disuelto el contrato ${ }^{15}$.

Pero, cuando surja controversia entre las partes, en cuanto al incumplimiento y a los presupuestos para la resolución, la sentencia del juez tendrá naturaleza meramente declarativa, limitándose a verificar si la declaración de resolución se efectuó en presencia o en ausencia de los presupuestos de ley.

Por tanto, el derecho a la resolución del contrato puede asumir en el derecho español, las características de un "derecho potestativo de disolución del contrato", que surge a causa del incumplimiento del deudor.

Los presupuestos que -según la elaboración de la doctrina y de la jurisprudencia- hacen legítima la declaración de resolución son los siguientes ${ }^{16}$ :

a) La reciprocidad de las obligacione ${ }^{17}$;

b) La violación de una obligación principal que deriva del contrato ${ }^{18}$;

15 La falta de contestación de los presupuestos de la resolución por parte del deudor que incumple perfecciona un acuerdo resolutorio, que no difiere de la resolución consensual y que halla su propio fundamento en la norma general que reconoce la autonomía negocial de las partes (art. 1255: Los contratantes pueden establecer los pactos, cláusulas y condiciones que tengan por conveniente, siempre que no sean contrarios a las leyes, a la moral, ni al orden público).

16 Sobre este punto ver Álvarez Vigaray, op. cit., 175-276.

17 Reciprocidad de las obligaciones, que la jurisprudencia española interpreta con rigor en el sentido de la interdependencia funcional de las obligaciones, hasta el punto, por ejemplo, de reconocer la resolución del contrato de compraventa en favor del vendedor por incumplimiento de la obligación de pago del precio por parte del vendedor, el cual había hecho valer la exceptio inadimplenti non est adimplendum en relación con el rechazo del vendedor de repetir el contrato en la forma del acto público: el incumplimiento del vendedor, en efecto - a criterio del Tribunal Supremo- atiene a "aspectos accesorios o complementarios" (STS 9 de julio de 1993; STS 12 de julio de 1991, ambas comentadas por De la Haza Diaz, El incumplimiento resolutorio. Análisis de jurisprudencia del Tribunal Supremo, Madrid, 1996, 8.

18 Y es tal aquella obligación que constituye el medio principal para conseguir el resultado típico del contrato, o bien aquélla que sirva a completar y garantizar la actuación de las obligaciones principales: Clemente Meoro, La resolutión de los contratos por incumplimiento, Valencia, 1992, 127. 
c) La gravedad del incumplimiento: entendida no sólo como incumplimiento definitivo y total, sino también como cumplimiento defectuoso, parcial o retardado, que prive al acreedor del interés a recibir la prestación ${ }^{19}$.

La declaración unilateral de resolución del contrato encuentra, además, en el Código civil español significativas confirmaciones sistemáticas en algunas normas sobre los contratos singulares, en las cuales el remedio resolutorio está textual y claramente configurado a manera de un derecho potestativo de desistimiento, sometido solamente a determinación judicial ex postea en cuanto a sus presupuestos sustanciales de ejercicio. Así es, por ejemplo, en el art. 1454 (que consiente la disolución del contrato en caso de dación de $\operatorname{arras}^{20}$ ), en el art. 1486 (en tema de vicios y defectos de la cosa vendida), en el art. 1504 (que prevé la resolución "de pleno derecho" de la venta inmobiliaria por falta de pago del precio, a salvo la facultad del comprador de pagar hasta que le sea dirigida la intimación judicial o por acto notarial21).

Al evaluar las consecuencias de tan fecunda elaboración del dato normativo, la doctrina española ${ }^{22}$ ha afirmado expresamente que el sistema de resolución por declaración unilateral se revela más

19 Dell'aquila E., La resolución, cit., 178 ss.; De la Haza Diaz, op cit. 20. Para el Derecho italiano, sobre los criterios de aplicación del art. 1455, por todos, Cubeddu, L'importanza dell'inadempimento, Torino, 1995, 17 ss.

20 No obstante, la norma no presenta el tecnicismo de nuestro art. 1385 c.c., ya que no distingue entre finalidad confirmatoria y finalidad penitencial. Ahora bien, la jurisprudencia española entiende que, en la duda interpretativa acerca de la dación de la suma de dinero, se debe preferir la calificación en términos de pago parcial sobre el precio (ex plurimis, STS 11 de abril de 1994; STS 7 de febrero de 1986). La solución es criticada por la doctrina que excluye, también, que la norma tenga naturaleza excepcional (Díez Picazo-Gullón, Sistema de derecho civil, II, 9a ed., Madrid, 2001, 266).

21 Por tanto, "el incumplimiento no determina automáticamente la resolución, sino que es un presupuesto con el fin de que el vendedor ejerza su derecho potestativo de resolución": así, Díez Picazo-Gullón, op. cit., 285.

22 Sobre el punto, Diez Picazo, op. cit., 56. Para la mayor rapidez y practicidad de la resolución por declaración unilateral, Álvarez Vigaray, op. cit., 283. conveniente y mayormente adecuado a la protección de los respectivos intereses involucrados en la relación contractual.

En particular, en el caso que el acreedor no deba repetir la prestación ya ejecutada (por no haberla ejecutado aún), la necesidad de recurrir al juez para obtener la disolución del vínculo contractual constituiría un "bloqueo" de su situación económico-patrimonial, por la imposibilidad de disponer de los bienes objeto de la prestación, sobre los cuales permanece el derecho de crédito de la contraparte que incumplió hasta el pronunciamiento judicial constitutivo de la resolución del contrato.

\section{LA RESOLUCIÓN POR INCUMPLIMIENTO EN EL BGB DE 1896 Y LAS ALTERNATIVAS DE OTROS SISTEMAS JURÍDICOS}

También el examen de la disciplina contenida en el BGB -ya en la originaria formulación antecedente a la reciente reforma del Schuldrecht- induce a configurar el remedio resolutorio acogido por dicho ordenamiento a manera de una declaración unilateral de la parte que no incumple.

Sin embargo, es preciso señalar que la Pandectística, previamente, se había mostrado, de manera decidida, contraria a una regla general de resolución del contrato por incumplimiento, dejando a salvo la sola hipótesis en que la resolución fuera pactada convencionalmente ${ }^{23}$.

Viceversa, el $B G B$ introduce el derecho de resolver el contrato frente a la imposibilidad de la prestación imputable a la contraparte, poniendo tal derecho como alternativo al de demandar el resarcimiento del daño $(\S 325)^{24}$.

23 Windscheid, Diritto delle Pandette, trad. Fadda e Bensa, II, Torino 1930, 248.

24 En caso de mora, es preciso, distinguir: si la mora determina la pérdida del interés a la ejecución del contrato, la parte fiel puede pretender el resarcimiento del daño o, en alternativa, desligarse del contrato; por otro lado, puede fijar un plazo, a fin de que el deudor ejecute tardíamente la prestación, vencido sin que se haya producido el cumplimiento, el acreedor puede nuevamente optar 
La clara elección de confiar al contratante la facultad de desligarse del contrato como consecuencia del incumplimiento testimonia la progresiva emancipación del modelo romanista de la "condición resolutoria tácita", que demostraba su inconveniencia en correspondencia con el desarrollo y la internacionalización del tráfico económico.

Al modelo del $B G B$ se uniformó en parte el Código civil austriaco luego de las Novelas de los años 1914-1916, que -diversamente de la versión originaria- reconocieron al contratante inocente el derecho de desligarse del contrato después de haber fijado al deudor un término para el cumplimiento tardío (§ 918).

Los sistemas anglosajones, a su vez, siempre han optado por el modelo de resolución del contrato mediante declaración unilateral del acreedor de la prestación incumplida o cumplida de manera inexacta o con retraso.

Se puede afirmar que, hasta los últimos decenios del siglo XX, la acción judicial de resolución y la resolución por incumplimiento representan dos modelos, tendencialmente -mas no necesariamente- alternativos, para disciplinar una reacción al incumplimiento -la resolución del contrato- que se revela, en muchos casos, más conveniente que las acciones coercitivas de cumplimiento.

Mientras el ordenamiento francés, el italiano y los Códigos latinoamericanos (en particular, el Código colombiano -con el art. 1546- y el peruano) confían, como regla, la necesaria intervención del juez, el legislador alemán, el sistema inglés

entre resarcimiento del daño e desistimiento del contrato (§ 326). El derecho al desistimiento inmediato de la relación contractual está previsto, además, cuando las partes hayan establecido que la prestación se deba ejecutar en un determinado momento o en un cierto plazo (§361). El texto orioinal del BGB preveía, en fin, que el desistimiento por incumplimiento (der Rücktritt) fuera regulado por las normas sobre la disolución convencional del contrato ( $\S \S 346-356$ ), que deriva de una específica cláusula contractual y que tiene funciones generalmente penitenciales y distintas de la necesidad de poner remedio a una sobrevenida violación del reglamento contractual. y la jurisprudencia española, comprendiendo la mayor funcionalidad del derecho potestativo de disolución unilateral frente las exigencias del contratante inocente, prefieren enlazar la resolución del contrato a la declaración unilateral del contratante fiel.

\section{EL CÓDIGO CIVIL ITALIANO DE 1942}

El Código Civil italiano de 1942 acoge un sistema que podemos definir "mixto". La regla es la resolución judicial, pero son numerosas las hipótesis en que la disolución del contrato se puede producir a través de la manifestación de la voluntad unilateral del acreedor. Y ello puede ocurrir no solamente en la disciplina de algunos contratos (por ejemplo, el contrato de trabajo subordinado), sino también en el plano de la disciplina general, a través de una pluralidad de institutos como:

- La intimación por cumplir: el negocio unilateral con el cual el acreedor "amenaza" al deudor que, en caso de que no cumpla dentro de un breve plazo, el contrato se disolverá automáticamente;

- La cláusula resolutoria expresa, en la cual las partes establecen al momento de la conclusión del contrato que, en el caso de incumplimiento de una particular obligación según específicas modalidades, el acreedor podrá desligarse unilateralmente del contrato;

- Las arras confirmatorias: la falta, en tal caso, de la oportunidad de confiar al juez la discrecionalidad de liquidación del daño ha inducido al legislador a permitir a la parte acreedora desligarse del contrato a causa del incumplimiento de la otra parte.

También en el sistema italiano la jurisprudencia -a la par de cuanto ha ocurrido en el sistema español- procede (con timidez) a la progresiva transformación de la resolución judicial en el modelo de la resolución por incumplimiento. Es muy significativa en este sentido una sentencia de las 
Secciones Unidas de la Corte de Casación ${ }^{25}$ italiana, que permite al acreedor rechazar el incumplimiento tardío cuando el retraso sea ya de no escasa importancia, aún cuando él no haya propuesto todavía la demanda judicial de resolución.

Afirman los Supremos Jueces italianos que, si el incumplimiento es "importante" e imputable, el acreedor no puede ser constreñido a recibir una prestación en la que ha perdido interés y puede, por tanto, rechazarla legítimamente. Es evidente cómo, en tal caso, un sucesivo pronunciamiento del Juez se limitará a "verificar" si el rechazo fue legítimo y si, por ende, fue legítima la pretensión del acreedor de entender el contrato como resuelto.

\section{¿HACIA LA UNIFICACIÓN DE LOS MODELOS DE RESOLUCIÓN?}

La unificación de los modelos de resolución no es tal vez lejana, como se puede colegir de los textos normativos de derecho internacional. Es bastante significativa, a tal fin, la Convención de Viena de 1980 en materia de venta internacional de bienes muebles.

Profundamente inspirada por el sistema anglosajón, la Convención de Viena atribuye al comprador, en presencia de vicios de la cosa adquirida, un rico abanico de remedios, como el requerimiento de eliminación de los vicios, de sustitución de la cosa, de reducción del precio y, naturalmente, la resolución del contrato. Tal remedio resolutorio presupone la gravedad del vicio de la cosa y se realiza a través de la declaración unilateral del comprador.

La Convención de Viena ha asumido en Europa una importancia fundamental, ya que ha sido el modelo normativo de la Directiva No 44 de 1999 en materia de venta de bienes muebles de consumo. También este texto, en efecto, ha acogido la declaración unilateral de resolución por incumplimiento en lugar de la resolución judicial y ha

25 Cass., sez. un, 9 de julio de 1997 n. 6224. sido recibido con estas características incluso en aquellos ordenamientos -como el italiano- tradicionalmente caracterizados por la reacción judicial al incumplimiento.

Por ejemplo, el Código de Consumo italiano de 2005 disciplina la resolución del contrato por vicios del bien de consumo como un remedio ciertamente de naturaleza sustancial y no judicial. Asimismo, los otros textos de derecho europeo -los principios Lando, el Código Gandolfi de los jusprivatistas europeos y, recientemente, los principios del acquis communitaire- optan también ellos por la declaración unilateral de resolución, abandonando completamente la necesidad de dirigirse al Juez para obtener un pronunciamiento constitutivo.

Por tanto, es inevitable que se plantee el problema de la oportunidad de superar definitivamente el modelo judicial y acoger una diversa interpretación de las normas generales del Código civil en el sentido de transformar el juicio de resolución en una verificación por parte del Juez de la legitimidad de la voluntad unilateral de resolución del contrato por el incumplimiento de uno de los contratantes.

No es posible examinar analíticamente todas las consecuencias y, en particular, las ventajas del modelo del desistimiento por incumplimiento, pero sintéticamente se puede afirmar que la declaración unilateral de resolución puede consentir una deflación de la litigiosidad judicial en el caso en que el deudor evalúe que la pretensión contraria sea probablemente fundada.

La consideración de la producida disolución del contrato consentirá al acreedor accionar para la restitución de la eventual contraprestación ejecuta$\mathrm{da}$, eventualmente incluso por medio de acciones cautelares y de urgencia.

Por ejemplo, en materia de contrato de locación o de obra (appalto), la disolución del contrato permitirá entender ilegítima la detención de la res 
por parte del contratista o del conductor desde el momento de la comunicación de la declaración de resolución.

Por tanto, se puede afirmar que con el abandono del instituto del término dilatorio que -según el Código Napoleónico- el juez podía benévolamente conceder al deudor para sanar su retraso o su incumplimiento, no hay más razones para privar a los contratantes de la autorresponsabilidad en los eventos que pueden conducir a la disolución del vínculo contractual.

\section{UNA MIRADA AL CÓDIGO CIVIL COLOMBIANO}

Me parece poder afirmar que el problema de la naturaleza judicial o sustancial de la resolución del contrato por incumplimiento se plantea también en el sistema colombiano, y estoy feliz de que este Congreso me haya dado la oportunidad de estudiar algunas partes del Código civil de este espléndido país.

El art. 1546 se remonta al Código francés y acoge la condición resolutoria tácita, que requiere el pronunciamiento del juez para obtener la resolución del contrato. Sólo el art. 1882, en materia de compraventa, hace referencia a un desistimiento sobre el cual se discute su naturaleza sustancial o judicial.

He tenido ocasión de examinar un remoto pronunciamiento de la Casación Civil (9 de Junio de 1971), en el cual textualmente se afirma que:
[...] existe notable diferencia entre la acción resolutoria prevista por el artículo 1546 del Código Civil y el desistimiento del que tratan los artículos 1882 y 1878 de la misma obra. Aquélla requiere sentencia judicial en que se decrete la resolución del contrato, en tanto que el derecho de desistir de la compraventa, en caso de que el vendedor por hecho o culpa suya haya retrasado la entrega de la cosa vendida, es un derecho potestativo del comprador que no requiere pronunciamiento alguno del Juez. Puede el comprador desistir por sí y ante el mero hecho de haber incurrido el vendedor en mora, y pedir la indemnización que los citados artículos le reconocen.

Si no entiendo mal, ésta concepción del desistimiento es bastante cercana al derecho potestativo de resolución, que muchos códigos europeos y textos de derecho europeo afirman y reconocen.

Por el contrario, el desistimiento al que hace mención el art. 22 de la Ley 820 de 2003 en materia de locación alude a una demanda que repropone el modelo judicial y se aleja de los modernos principios afirmados por la Casación en 1971.

Estoy convencido de que la reflexión de muchos de los juristas presentes en este Congreso podrá contribuir a reproponer el debate sobre la diferencia entre acción resolutoria y desistimiento y contribuir finalmente a la elaboración de un único modelo, europeo y latinoamericano, en tema de disolución del contrato por incumplimiento. 